\title{
Small Interfering RNA Targeting Mitochondrial Calcium Uniporter Improves Cardiomyocyte Cell Viability in Hypoxia/Reoxygenation Injury by Reducing Calcium Overload
}

\author{
Yuriana Oropeza-Almazán, ${ }^{1}$ Eduardo Vázquez-Garza, ${ }^{1}$ Héctor Chapoy-Villanueva, \\ Guillermo Torre-Amione, ${ }^{1,2,3}$ and Gerardo García-Rivas ${ }^{1,2}$ \\ ${ }^{1}$ Cátedra de Cardiología y Medicina Vascular, Escuela de Medicina, Tecnológico de Monterrey, Monterrey, NL, Mexico \\ ${ }^{2}$ Centro de Investigación Biomédica, Hospital Zambrano-Hellion, San Pedro Garza-García, NL, Mexico \\ ${ }^{3}$ Methodist DeBakey Heart and Vascular Center, The Methodist Hospital, Houston, TX, USA \\ Correspondence should be addressed to Gerardo García-Rivas; gdejesus@itesm.mx
}

Received 6 October 2016; Revised 24 December 2016; Accepted 5 January 2017; Published 27 February 2017

Academic Editor: Leopoldo Aguilera-Aguirre

Copyright (C) 2017 Yuriana Oropeza-Almazán et al. This is an open access article distributed under the Creative Commons Attribution License, which permits unrestricted use, distribution, and reproduction in any medium, provided the original work is properly cited.

\begin{abstract}
Intracellular $\mathrm{Ca}^{2+}$ mishandling is an underlying mechanism in hypoxia/reoxygenation (H/R) injury that results in mitochondrial dysfunction and cardiomyocytes death. These events are mediated by mitochondrial $\mathrm{Ca}^{2+}\left(m \mathrm{Ca}^{2+}\right)$ overload that is facilitated by the mitochondrial calcium uniporter (MCU) channel. Along this line, we evaluated the effect of siRNA-targeting MCU in cardiomyocytes subjected to H/R injury. First, cardiomyocytes treated with siRNA demonstrated a reduction of MCU expression by $67 \%$, which resulted in significant decrease in mitochondrial $\mathrm{Ca}^{2+}$ transport. siRNA treated cardiomyocytes showed decreased mitochondrial permeability pore opening and oxidative stress trigger by $\mathrm{Ca}^{2+}$ overload. Furthermore, after H/R injury MCU silencing decreased necrosis and apoptosis levels by $30 \%$ and $50 \%$, respectively, and resulted in reduction in caspases $3 / 7$, 9 , and 8 activity. Our findings are consistent with previous conclusions that demonstrate that MCU activity is partly responsible for cellular injury induced by $\mathrm{H} / \mathrm{R}$ and support the concept of utilizing siRNA-targeting $\mathrm{MCU}$ as a potential therapeutic strategy.
\end{abstract}

\section{Introduction}

Coronary heart disease (CHD) is the leading cause of death in industrialized and third-world countries [1]. The effects of CHD are associated with the negative effects of ischemiareperfusion. Ischemia-reperfusion injury normally arises in patients presenting myocardial infarction with acute STsegment elevation in which timely and effective myocardial reperfusion is limiting the infarct size and death. However, several events that appear during myocardial reperfusion can induce further cell damage in a phenomenon known as reperfusion injury [2].

Numerous experimental studies have identified some critical factors that act in concert to mediate the unfavorable effects of reperfusion injury. First, intracellular and mitochondrial $\mathrm{Ca}^{2+}\left(\mathrm{mCa}^{2+}\right)$ overload are exacerbated during reperfusion due to oxidative stress-induced disruption of the sarcolemma and sarcoplasmic reticulum membranes [3]. Second, mitochondrial reenergization during reoxygenation allows the recovery of the membrane potential that drives the $\mathrm{Ca}^{2+}$ uptake into the mitochondria through the mitochondrial $\mathrm{Ca}^{2+}$ uniporter (MCU) channel and subsequently induces $\mathrm{mCa}^{2+}$ overload [4]. These events result in mitochondrial dysfunction, leading to cardiomyocyte death by the opening of the mitochondrial transition pore $\left({ }_{m} \mathrm{PTP}\right)$ [5]. Accordingly, targeting oxidative stress and/or modulating the activity of MCU by a selective blocker such as $\mathrm{Ru}_{360}[6,7]$ or the inhibition of ${ }_{m}$ PTP opening by cyclosporine A (CsA) provide specific targets for intervention [8].

The role of MCU in the regulation of $m \mathrm{Ca}^{2+}$ overload is supported by the observations that, in a model of cardiac 
ischemia-reperfusion, treatment with $\mathrm{Ru}_{360}$ decreased the $\left[\mathrm{Ca}^{2+}\right]_{m}$ and maintained mitochondrial ATP synthesis [6]. $\mathrm{Ru}_{360}$-treated hearts following in vivo reperfusion were less prone to undergo mitochondrial permeability transition $\left({ }_{m}\right.$ PTP) and apoptosis $[9,10]$. The recent description of the molecular identity of the MCU channel $[11,12]$ and several subunits that are crucial for $m \mathrm{Ca}^{2+}$ uptake allowed for the development of adult heart-specific transgenic models [13]. In this regard, conditional cardiac-specific $\mathrm{MCU}^{-/-}$mice subjected to reperfusion resulted in significant reduction of $\mathrm{mCa}^{2+}$ overload that disabled the activation of ${ }_{m}$ PTP and inhibited cardiomyocytes apoptosis and necrosis [14, 15]. These data together provide experimental rationale to develop strategies to target MCU activity with the purpose of preventing ischemic-reoxygenation injury.

On the other hand, small interfering RNA- (siRNA-) based treatments provide a potential therapeutic strategy to block MCU activity. Of interest, several phases I and II clinical studies involving patients with hepatitis, hypercholesterolemia, macular degeneration, and solid tumors have been completed [16] and appear to be safe strategy for gene therapy in humans [17].

Therefore, the purpose of this study was to explore the potential use of siRNA-targeting MCU in an in vitro model of hypoxia/reoxygenation $(\mathrm{H} / \mathrm{R})$ injury. Our results confirm previous observations that define the MCU as an essential modulator of the detrimental effects of reperfusion injury and suggest that MCU silencing using siRNA has the therapeutic potential to be used as a cardioprotective strategy.

\section{Materials and Methods}

2.1. Reagents. All chemical reagents, cell culture media and supplements, siRNA, and fluorescent probes were purchased from Sigma-Aldrich (St. Louis, MO, USA), unless otherwise stated.

2.2. MCU siRNA Sequence. To silence MCU, specific siRNA sequence was designed using RNAi siDirect v2.0 with the lowest predicted off-target potentials and 100\% homology with the rat gene (NCBI Reference Sequence NM_ 001106398.1). Then, we used siRNA-MCU Calcium1, nt 761779 of the corresponding mRNA, sense strand sequence: 5'-CGGCUUACCUGGUGGGAAU-3'. siRNA duplex was synthesized by Sigma-Aldrich (St. Louis, MO, USA). The nontargeting siRNA sequence is the MISSION ${ }^{\circledR}$ siRNA Universal Negative Control \#1 (SIC001) named as siRNA-Neg.

2.3. Cell Culture and siRNA Transfection. Rat ventricular myocardial H9c2 cell line (CRL-1446 ${ }^{\mathrm{TM}}$ ) was obtained from ATCC $^{\circledR}$ (Manassas, VA, USA). Cells were grown in Dulbecco's modified Eagle's medium (DMEM) (D7777) and supplemented with $10 \%$ fetal bovine serum (FBS) Invitrogen (Carlsbad, CA, USA) and 1x penicillin-streptomycin (P4333) in a humidified incubator at $37^{\circ} \mathrm{C}$ with $5 \% \mathrm{CO}_{2}$ and $95 \%$ air. For MCU silencing, H9c2 cells were seeded at $2.5 \times 10^{4}$ cells per well in 12 -well plates and $24 \mathrm{~h}$ later were transfected with $18.8,112.5$, or $225 \mathrm{nM}$ of siRNA-MCU designed or siRNA-Neg using the HiPerFect ${ }^{\mathrm{TM}}$ Transfection Reagent (Qiagen ${ }^{\circledR}$, Venlo, Netherlands), according to the manufacturer's protocols.

2.4. RNA Extraction, Reverse Transcription, and Gene Expression Analysis by Quantitative PCR. For the gene expression analysis of MCU silencing, after $96 \mathrm{~h}$ of transfection, total RNA was isolated from $\mathrm{H} 9 \mathrm{c} 2$ cells by homogenization in TriReagent ${ }^{\mathrm{TM}}$ following manufacturer's instructions. The RNA quantification and purity assessment was performed with a Take $3^{\mathrm{TM}}$ Micro-Volume plate used in the microplate spectrophotometer Synergy ${ }^{\mathrm{TM}}$ HT (BioTek $^{\circledR}$ Instruments, Winooski, VT, USA). From one microgram of total RNA of each sample, cDNA was synthesized with the ImProm-II ${ }^{\mathrm{TM}}$ Reverse Transcription System (Promega ${ }^{\circledR}$, Madison, WI, USA) and $5 \mathrm{ng}$ was analyzed by qRT-PCR SensiFast ${ }^{\mathrm{TM}}$ SYBR $^{\circledR}$ Lo-Rox Kit (Bioline ${ }^{\circledR}$, London, UK). The housekeeping gene $\beta$-actin was used to normalize all data. Real-time PCR primer sequences to amplify a fragment of $158 \mathrm{bp}$ of CCDC109A (MCU) gene are the following: fw, $5^{\prime}$-CACACAGTTTGGCATTTTGG-3', and $\mathrm{rv}, 5^{\prime}$-TGTCTCTGGCTTCAGGATAA- $3^{\prime}$. The primer sequences to amplify a fragment of $110 \mathrm{bp}$ of $\beta$-actin are fw, $5^{\prime}$-GAAAAGATGACCCAGATCATG-3', and rv, $5^{\prime}$-ATCACAATGCCAGTGGTAC-3'. Comparing expression analysis in siRNA-MCU cells to siRNA-Neg cells was performed using $2^{-\Delta \Delta \mathrm{Ct}}$ method.

2.5. Western Blot Assay. Cell proteins were extracted after $96 \mathrm{~h}$ of $\mathrm{H} 9 \mathrm{c} 2$ transfection, as previously described [18]. Briefly, after being washed with cold PBS, cell cultures were scraped, harvested, and resuspended in RIPA buffer. The samples were vortexed and sonicated on rounds of $10 \mathrm{sec}$ sonication $/ 10 \mathrm{sec}$ rest and centrifuged at $15000 \times \mathrm{g} 10 \mathrm{~min}$. The protein concentration of the lysate was determined by Lowry protein assay. Protein lysates $(30 \mu \mathrm{g} / \mathrm{lane})$ were resolved on SDS-PAGE gel 10\%, transferred onto PVDF membrane at $150 \mathrm{~mA}, 50 \mathrm{~min}$, and incubated with anti-MCU antibody ab121499 (Abcam, Cambridge, MA, USA) 1:500 and washed three times for $10 \mathrm{~min}$ with PBS-Tw $0.5 \%$ and subsequently probed with secondary antibody anti-rabbit IgG conjugated with HRP (Millipore, Billerica, MA, USA) 1:5000 for $2 \mathrm{~h}$ at room temperature (RT). After washing three times for $10 \mathrm{~min}$, protein-antibody blots were developed with Clarity ${ }^{\mathrm{TM}}$ Western ECL (Bio-Rad, Hercules, CA) and quantified by using a BioSpectrum 415 Image Acquisition System (UVP ${ }^{\circledR}$, Upland, CA, USA). Anti- $\beta$-actin antibody (ab8229) 1:500 or anti-GAPDH antibody (ab9484) 1:500 (both of them from Abcam, Cambridge, MA, USA) was used as a loading control. The level of MCU expression was the ratio of intensities of the MCU-signal/ $\beta$-actin signal normalized versus siRNANeg signal.

2.6. Measurement of the Mitochondrial $\mathrm{Ca}^{2+}$ Uptake. Cytosolic-free $\mathrm{Ca}^{2+}$ was monitored in digitonin-permeabilized $\mathrm{H} 9 \mathrm{c} 2$ transfected cells. Briefly, $5 \times 10^{4}$ cells were washed three times in Tyrode solution (in mM: $128 \mathrm{NaCl}, 0.4 \mathrm{NaH}_{2} \mathrm{PO}_{4}$, 5 glucose, $5.4 \mathrm{KCl}, 0.5 \mathrm{MgCl}-6 \mathrm{H}_{2} \mathrm{O}$, and $25 \mathrm{HEPES}, \mathrm{pH}$ 7.4) without $\mathrm{Ca}^{2+}$ and resuspended in $50 \mu \mathrm{L}$ of respiration 
buffer containing in $\mathrm{mM}$ the following: 150 sucrose, 50 $\mathrm{KCl}, 2 \mathrm{KH}_{2} \mathrm{PO}_{4}, 20$ Tris- $\mathrm{HCl} \mathrm{pH} 7.3,5$ succinate, $2 \mu \mathrm{g} / \mathrm{mL}$ rotenone, $40 \mu \mathrm{M}$ digitonin, $0.5 \mu \mathrm{M}$ thapsigargin (TG), $1 \mu \mathrm{M}$ CsA, $0.3 \mu \mathrm{M}$ Calcium Green-5N (CG-5N) salt-free (Thermo Fisher Scientific, Waltham, MA, USA). CG-5N fluorescence $\left(\lambda_{\mathrm{ex}} 485 \mathrm{~nm} / \lambda_{\mathrm{em}} 528 \mathrm{~nm}\right)$ was monitored at $25^{\circ} \mathrm{C}$ at basal conditions and after $15 \mu \mathrm{M} \mathrm{Ca}^{2+}$ addition with constant agitation using a microplate fluorescence spectrophotometer Synergy HT (BioTek Instruments, Winooski, VT, USA).

2.7. Mitochondrial Membrane Potential $\left(\Delta \psi_{m}\right)$ and ${ }_{m} P T P$ Measurements. Safranin was used to assess $\Delta \psi_{m}$ in digitoninpermeabilized transfected cardiomyocytes as previously described by Oliveira et al. [19], with some modifications. Briefly, $5 \times 10^{4} \mathrm{H} 9 \mathrm{c} 2$ transfected cells were washed and resuspended as already stated in $50 \mu \mathrm{L}$ of respiration media with $2 \mu \mathrm{M}$ safranin. Safranin fluorescence was recorded at $\lambda_{\mathrm{ex}} 485 \mathrm{~nm}$ and $\lambda_{\mathrm{em}} 590 \mathrm{~nm}$ using a microplate fluorescence reader. After $5 \mathrm{~min}, 10 \mathrm{mM}$ succinate was added as substrate until steady state was reached. $\mathrm{A} \mathrm{Ca}^{2+}$ pulse of 7.5 or $15 \mu \mathrm{M}$ was added to induce permeability transition, and $1 \mu \mathrm{M}$ cyclosporin A (CsA) or $0.5 \mu \mathrm{M} \mathrm{Ru}_{360}$ was used as pharmacological inhibitors of ${ }_{m}$ PTP opening and MCU, respectively. Cyanide $m$-chlorophenyl hydrazone (CCCP, $20 \mu \mathrm{M})$ was added when indicated to dissipate $\Delta \psi_{m}$. Depolarization was measured after $13 \mathrm{~min}$ of $\mathrm{Ca}^{2+}$ addition. Experimental data were normalized to the maximum safranin fluorescence $(100 \% \Delta \psi)$, calculated as the difference between the steady state fluorescence and after addition of CCCP.

To support that $\mathrm{Ca}^{2+}$ induces ${ }_{m}$ PTP opening, with $5 \times 10^{4}$ $\mathrm{H} 9 \mathrm{c} 2$ permeabilized transfected cardiomyocytes in respiration media, we carried out a $\mathrm{Ca}^{2+}$ retention experiment with a single $50 \mu \mathrm{M} \mathrm{Ca}^{2+}$ bolus using CG-5N as a $\mathrm{Ca}^{2+}$ indicator. The experiment was performed with $(1 \mu \mathrm{M})$ or without CsA.

2.8. Flow Cytometry Measurements. Transfected cardiomyocytes were stained and analyzed in a FACSCanto $\mathrm{II}^{\mathrm{TM}}$ Flow Cytometer (BD Bioscience, San Jose, CA), and each time point analysis consisted of 5,000 recorded events. Cell morphology was assessed by analyzing the Forward Scatter (FSC) and Side Scatter (SSC) parameter and we excluded doublets by FSC-A/FSC-W gating. Debris was discarded by its distinct low Forward and Side Scatter. Samples were run uncompensated and the FMI analysis was performed using the FlowJo ${ }^{\mathrm{TM}}$ vX.07 (Tree Star, Ashland, OR, USA).

2.8.1. Measurements of ROS Production. To assess mitochondrial ROS (superoxide) production, transfected cardiomyocytes were stained with MitoSOX Red (Thermo Fisher Scientific), as previously reported by Mukhopadhyay et al. [20]. Briefly, cells were allowed to load MitoSOX for $30 \mathrm{~min}$ at $37^{\circ} \mathrm{C}$. After staining, the cells were washed with Tyrode solution. Finally, each sample was stimulated with TG at a concentration of $5 \mu \mathrm{M}$. Before TG addition, siRNA-Neg cardiomyocytes were incubated with or without $5 \mu \mathrm{M} \mathrm{Ru} 360$ for $30 \mathrm{~min}$ or $1 \mu \mathrm{M}$ CsA during $10 \mathrm{~min}$ as pharmacological inhibitors of superoxide production. Serial analysis of the samples was performed at different time points $(0.5,15,30$, 60 , and $120 \mathrm{~min})$. The data of the MitoSOX are presented as the fold increase of median intensity fluorescence against the siRNA-Neg controls.

2.8.2. Cytotoxicity Assay. Cell viability and apoptotic and necrotic cell death were measured by Annexin V/PI staining followed by flow cytometry analysis. Briefly, after normoxy (Nxy), hypoxia, and 1.5 and $3 \mathrm{~h}$ reoxygenation conditions, $\mathrm{H} 9 \mathrm{c} 2$ transfected cells were washed, resuspended in $195 \mu \mathrm{L}$ Tyrode $+2.5 \mathrm{mM} \mathrm{CaCl}_{2}$ solution, and stained with $5 \mu \mathrm{L}$ of Annexin V Apoptosis Detection Set PE-Cy7 88-8103 (eBioscience, San Diego, CA, USA) for $10 \mathrm{~min}$. Later, cells were washed and resuspended in $195 \mu \mathrm{L}$ Tyrode $+2.5 \mathrm{mM} \mathrm{CaCl}_{2}$ solution and incubated with $100 \mathrm{ng}$ of PI (P4170) to discard necrotic cells. Stained cells were immediately analyzed by flow cytometry. The assay was performed with a two-coloranalysis of PE-Cy7-labeled Annexin V binding and PI dye excited with $488 \mathrm{~nm}$ laser. To evaluate the proportions of viable, apoptotic, and necrotic cells, we performed fluorescence compensation. After discarding doublets, the living cells (Annexin $\left.\mathrm{V}^{-} / \mathrm{PI}^{-}, \mathrm{Q} 4\right)$, early apoptotic cells (Annexin $\left.\mathrm{V}^{+} / \mathrm{PI}^{-}, \mathrm{Q} 3\right)$, late apoptotic cells (Annexin $\left.\mathrm{V}^{+} / \mathrm{PI}^{+}, \mathrm{Q} 2\right)$, and necrotic cells (Annexin $\mathrm{V}^{-} / \mathrm{PI}^{+}$, Q1) were distinguished.

2.9. Measurement of ATP Content. Intracellular ATP content was measured in $96 \mathrm{~h}$ transfected cardiomyocytes, using the CellTiter-Glo ${ }^{\circledR}$ Luminescent Assay (Promega, Madison, USA), according to the manufacturer's protocol. The ATP content is expressed as luminescence relative units (LRU).

2.10. In Vitro Hypoxia/Reoxygenation Model. For hypoxic challenges, H9c2 transfected cells were trypsinized, washed with Tyrode without glucose, and incubated with a modified Tyrode solution simulating ischemic conditions (IT) (in mM: $135 \mathrm{NaCl}, 8 \mathrm{KCl}, 0.5 \mathrm{MgCl}_{2}, 0.33 \mathrm{NaH}_{2} \mathrm{PO}_{4}, 5$ HEPES, 1.8 $\mathrm{CaCl}_{2}$, and $20 \mathrm{Na}^{+}$-lactate, $\mathrm{pH}$ 6.8) [21] and transferred into an anaerobic chamber with an oxygen level $<1 \%$ at $37^{\circ} \mathrm{C}$. After $3 \mathrm{~h}$ hypoxia, cells were washed and incubated with Tyrode (plus $5 \mathrm{mM}$ glucose, $1.8 \mathrm{mM} \mathrm{CaCl}_{2}$ ) and transferred into an incubator in normoxic conditions $\left(37^{\circ} \mathrm{C}\right.$ with $5 \% \mathrm{CO}_{2}$ and $95 \%$ air) for 1.5 and $3 \mathrm{~h}$ for reoxygenation and analyzed for apoptosis and necrosis at each time. During hypoxia, an experimental group remained in normoxic conditions. A schematic representation of hypoxia/reoxygenation model is shown in Figure 1.

2.11. Caspase Activity Measurements. For caspase activity measurements, H9c2 were seeded at $1.5 \times 10^{3}$ cells per well in 96-well plates and $24 \mathrm{~h}$ later were transfected as described previously. After $96 \mathrm{~h}$ of transfection, the cells were washed with Tyrode, incubated with IT solution, and transferred into an anaerobic chamber with an oxygen level $<1 \%$ at $37^{\circ} \mathrm{C}$. After $3 \mathrm{~h}$ hypoxia, IT solution was removed and cells were incubated with DMEM at normoxic conditions $\left(37^{\circ} \mathrm{C}\right.$ with $5 \% \mathrm{CO}_{2}$ and $95 \%$ air) for $0,1.5$, and $3 \mathrm{~h}$ reoxygenation and analyzed for caspases 3 and 7 and caspases 8 and 9 activity at each time. During hypoxia, an experimental group remained in normoxic conditions. The activity of caspases 3 and 7 and caspase 9 and caspase 8 was measured using Caspase-Glo 3/7, 
Hypoxia/reoxygenation protocol

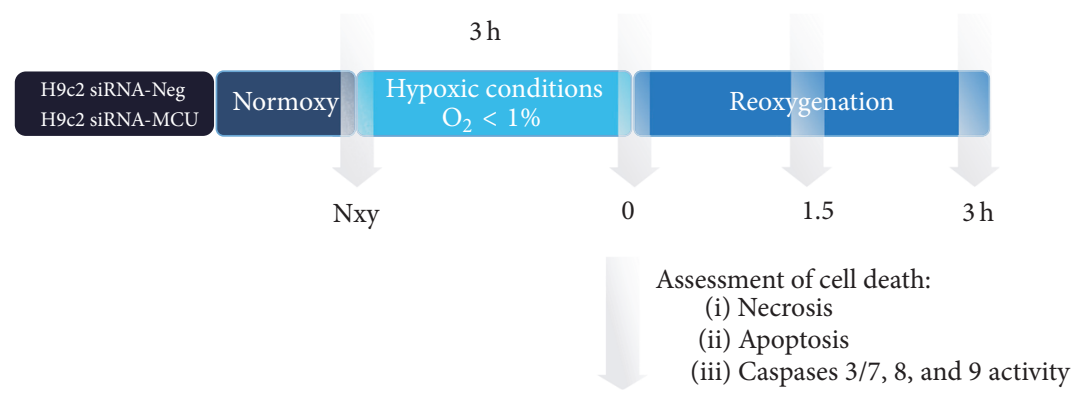

Figure 1: Schematic representation showing the hypoxia/reoxygenation (H/R) protocol applied to each experimental group. At normoxic conditions, siRNA-Neg (control group) and siRNA-MCU cardiomyocytes were subjected to $3 \mathrm{~h}$ of normothermic hypoxia (H) with an ischemic Tyrode solution (IT) followed by $3 \mathrm{~h}$ of reoxygenation (R). Transfected cardiomyocytes were harvested when indicated by arrows: measurements of necrosis and apoptosis by flow cytometry were performed and caspases 3 and 7 and caspases 9 and 8 activity were determined as described in Materials and Methods. Nxy, normoxy.

9, and 8 assay (Promega, Madison, WI, USA), respectively, according to the manufacturer's protocols.

2.12. Statistical Analysis. Statistical data are presented as mean \pm SEM. Comparisons between means were made by unpaired Student's $t$-test or one-way ANOVA followed by Dunnett's, Tukey's, or Bonferroni's post hoc tests when appropriate to compare experimental groups. Differences were considered significant when $P<0.05$. Data processing, graphs, and statistical analysis were performed with GraphPad Prism (V.5.01, La Jolla, CA, USA) and OriginPro 8.1 SR3 v8.1 (OriginLab Corporation, Northampton, MA, USA).

\section{Results}

3.1. siRNA-Targeting MCU Efficiently Decreases Mitochondrial $\mathrm{Ca}^{2+}$ Transport in Cardiomyocytes. Rat cardiomyocytes were transfected with specific MCU-targeted siRNA (siRNAMCU) or nonsilencing siRNA (siRNA-Neg) to investigate the role of MCU in cell death. Using $\mathrm{qPCR}$ assays, we determined that there was a $70 \% \pm 5(P<0.001)$ reduction in MCU mRNA expression levels up to $96 \mathrm{~h}$ after transfection (Figure 2(a)). Next, our silencing effects were verified using western blot assays. In cardiomyocytes transfected with the siRNA-MCU, MCU expression was lower than that in those transfected with siRNA-Neg cells. This effect showed a timedependent response with a $\sim 50 \%$ silencing at 48 and $72 \mathrm{~h}$ (Figure 2(b)). Moreover, at $96 \mathrm{~h}$ of transfection, we found significantly lower MCU protein levels by $67 \% \pm 8(P<$ $0.001)$. In addition, under this condition the concentration of MCU siRNAs used ( $225 \mathrm{nM}$ ) did not adversely affect the number of viable cells or the cardiomyocyte morphology and ATP production (Suppl. Figure 1A-E, Supplementary Material available online at https://doi.org/10.1155/2017/5750897). Based on these results, we used siRNAs at $225 \mathrm{nM}$ for $96 \mathrm{hrs}$ in the remainder of our experiments, in which we obtained the maximal silencing of MCU mRNA and protein expression (Figures 3(a) and 3(b)). In addition, siRNA-MCU did not modify the relative expression of other uniplex components, such as MICU1, MICU2, EMRE, and MCUR1 (Figure 2(c)).

Figure 3(c) shows representative $\mathrm{mCa}^{2+}$ uptake traces for the control and MCU-silenced cardiomyocytes. Permeabilized transfected cardiomyocytes were challenged with a $15 \mu \mathrm{M} \mathrm{Ca}^{2+}$ addition in the presence of $1 \mu \mathrm{M} \mathrm{CsA}$ to determine the maximum MCU activity [9]. In control cells, a rapid $m \mathrm{Ca}^{2+}$ entry was observed (completely abolished by $\mathrm{Ru}_{360}$, data not shown); however, in siRNA-MCU treated cells, the $\mathrm{Ca}^{2+}$ transport was drastically reduced. Mitochondrial $\mathrm{Ca}^{2+}$ uptake time to its $50 \%\left(T_{50 \%}\right)$ provides a quantitative index of MCU activity. For the control cardiomyocytes, $T_{50 \%}$ was $1.08 \pm 0.22 \mathrm{~min}$, while, in MCU-silenced cells, it was $2.02 \pm$ $0.4 \mathrm{~min}(P<0.05)$ (Figure $3(\mathrm{~d}))$. These results indicate a significant reduction in the rate of mitochondrial transport in our MCU-silenced cardiomyocytes.

3.2. MCU Silencing Reduces Mitochondrial $\mathrm{Ca}^{2+}$ Overload, Permeability Transition Pore, and Oxidative Stress in Cardiomyocytes. Since excessive $\mathrm{Ca}^{2+}$ accumulation in the mitochondrial matrix leads to the collapse of the mitochondrial potential, transfected cardiomyocytes were challenged with $\mathrm{Ca}^{2+}$ overload following their effects on the membrane potential. At a steady state, the membrane potential did not show a difference in $\Delta \psi_{m}$ between the control and MCUsilenced cardiomyocytes (Suppl. Figure 1C-D). Nevertheless, after a $\mathrm{Ca}^{2+}$ pulse, the control cardiomyocytes showed a significant $\mathrm{Ca}^{2+}$-dependent depolarization compared with MCU-silenced cardiomyocytes (Figure 4(a)). At the same time, MCU-silenced cells were able to maintain $\Delta \psi_{m}$ in $75 \%(P<0.05)$ (Figure 4(b)). $\mathrm{Ru}_{360}$ and CsA treatment protected against $\mathrm{Ca}^{2+}$-induced membrane depolarization by $\sim 95 \%$ (Figures 4(c) and 4(d) and Suppl. Figure 2A).

Moreover, in $\mathrm{Ca}^{2+}$ retention experiments with a $50 \mu \mathrm{M}$ $\mathrm{Ca}^{2+}$ bolus, we observed an early and dramatic release of $\mathrm{Ca}^{2+}$ from control cardiomyocytes compared with the MCUsilenced cells (Suppl. Figure 2B). $\mathrm{Ca}^{2+}$ release was inhibited 


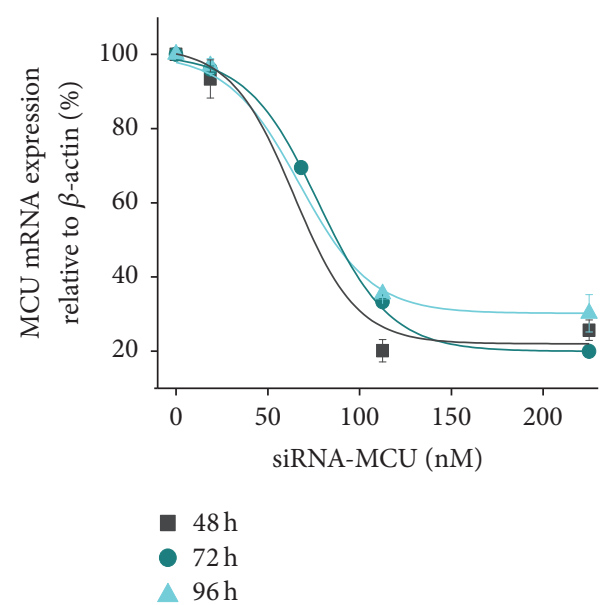

(a)

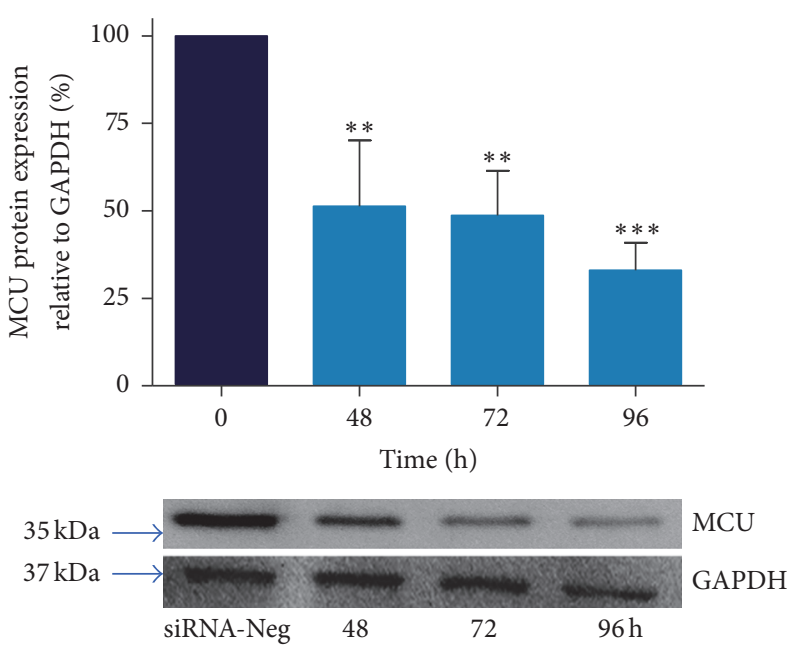

(b)

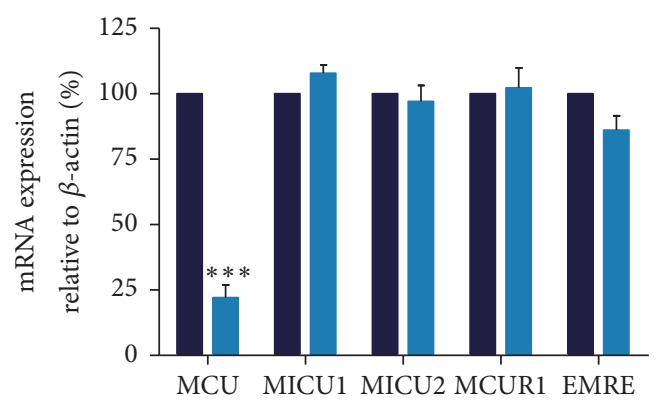

(c)

FIGURE 2: Dose-response analysis of MCU expression in cardiomyocytes transfected with a specific siRNA designed targeting MCU (siRNAMCU). (a) MCU mRNA expression by qRT-PCR normalized versus $\beta$-actin using $18.7,112.5$, or $225 \mathrm{nM}$ of siRNA at $0,48,72$, and $96 \mathrm{~h}$ of transfection. We obtained EC50 $\sim 67.2 \mathrm{nM}$ at $96 \mathrm{~h}$ of transfection, mean \pm SEM, $n=3$. (b) Representative protein expression analysis of MCU in cardiomyocytes silenced with $225 \mathrm{nM}$ of siRNA-MCU at $48 \mathrm{~h}\left({ }^{* *} \mathrm{P}<0.01\right)$; at $72 \mathrm{~h}\left({ }^{* *} \mathrm{P}<0.01\right)$; and at $96 \mathrm{~h}$ of transfection. GAPDH served as a loading control $\left({ }^{* * *} P<0.001\right)$, mean \pm SEM, $n=3-6$. (c) Relative mRNA abundance of associated regulatory genes in MCU-silenced cardiomyocytes using $225 \mathrm{nM}$ of siRNA-MCU at $96 \mathrm{~h}$ of transfection, mean \pm SEM, $n=4$. MICU1, mitochondrial calcium uptake 1; MICU2, mitochondrial calcium uptake 2; MCUR1, mitochondrial calcium uniporter regulator 1; EMRE, essential mitochondrial calcium uniporter regulator.

by CsA, indicating the involvement of ${ }_{m}$ PTP as a trigger of membrane potential collapse.

Oxidative stress and $\mathrm{Ca}^{2+}$ overload are known to have detrimental effects on mitochondrial membrane integrity since both are inducers of ${ }_{m}$ PTP opening [22]. Figure 5(a) shows the time-course analysis of superoxide production in response to TG-induced $\mathrm{Ca}^{2+}$ overload. At basal conditions, the control and MCU-silenced cardiomyocytes showed a similar fluorescence intensity of MitoSOX. After 60 and 120 min of TG treatment, MitoSOX intensity was significantly higher in siRNA-Neg transfected cells than in MCU-deficient cardiomyocytes (Figure 5(a)). Therefore, MCU-deficient cardiomyocytes showed a $51 \%(P<0.001)$ reduction in $\mathrm{Ca}^{2+}$ overload-induced superoxide production (Figure 5(b)). Under these conditions, the $\mathrm{Ru}_{360}$ and CsA treatment also decreases ROS production by $22 \%$ (ns) and $49 \%(P<0.001)$, respectively (Figure 5(c)). In accordance with these findings,
MCU silencing might exert protective effects by reducing oxidative stress induced by $\mathrm{Ca}^{2+}$ overload.

3.3. MCU Silencing Reduces Cardiomyocyte Cell Death in Hypoxia/Reoxygenation Injury. Transfected cardiomyocytes were incubated for $3 \mathrm{~h}$ in a hypoxic chamber for $\mathrm{O}_{2}$ (1\%) in combination with glucose-deprivation, serum-free, and acidosis ( $\mathrm{pH}$ 6.8) conditions to induce hypoxia. A schematic model of hypoxia/reoxygenation is shown in Figure 1. Cell viability and apoptosis were determined by Annexin V/PI staining and analyzed by flow cytometry at specific time points during Nxy and during reoxygenation: at the beginning $(0 \mathrm{~h})$, after $1.5 \mathrm{~h}$, and after $3 \mathrm{~h}$. Representative flow cytometry dot plots showing the populations of viable (Annexin $\mathrm{V}^{-}$, $\mathrm{IP}^{-}$) and apoptotic cells (Annexin $\mathrm{V}^{+} / \mathrm{IP}^{-}$and Annexin $\left.\mathrm{V}^{+} / \mathrm{IP}^{+}\right)$are shown in Figures 6(a) and 6 (b) at Nxy and $1.5 \mathrm{~h}$ of reoxygenation. Cell viability was 

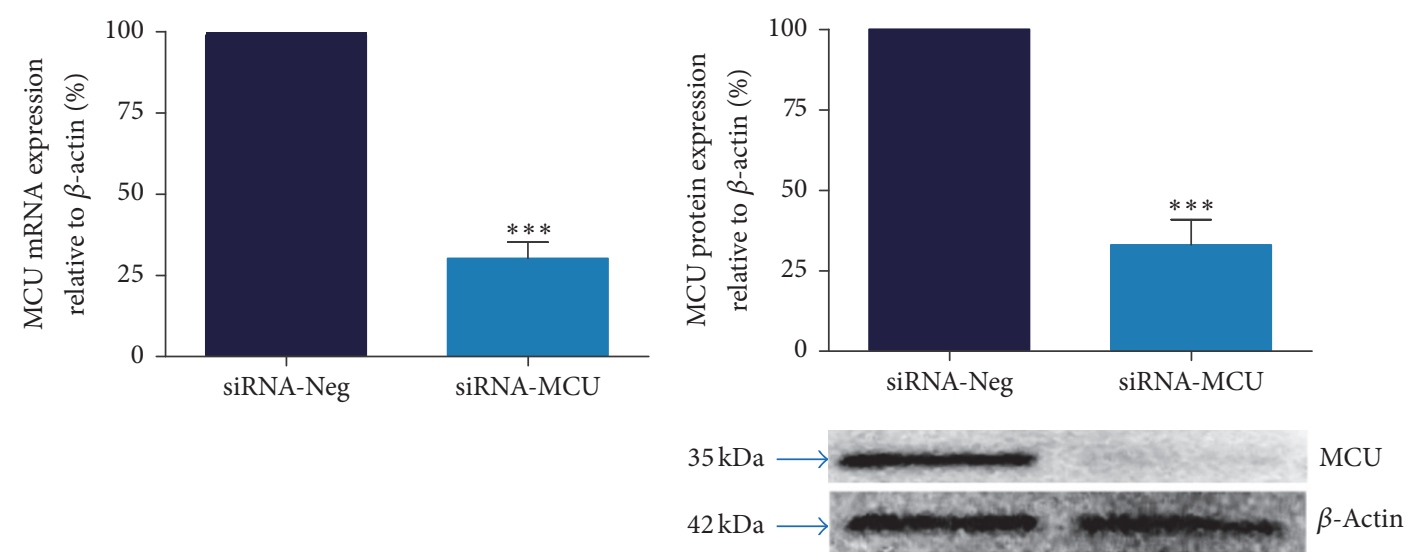

(a)

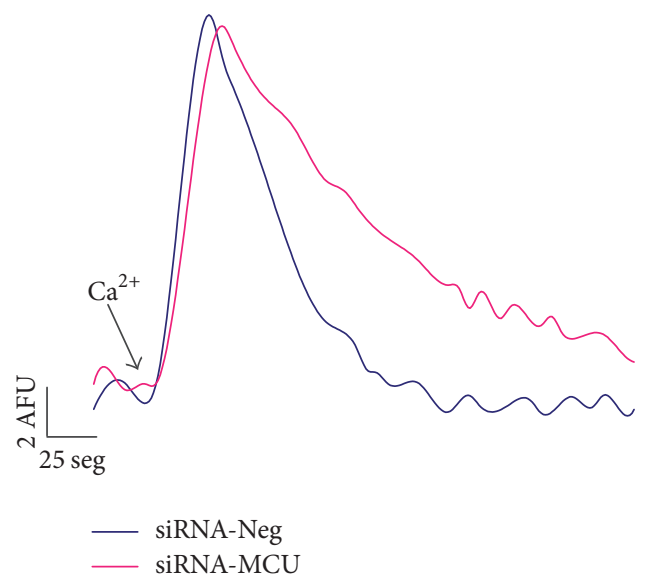

(c) (b)

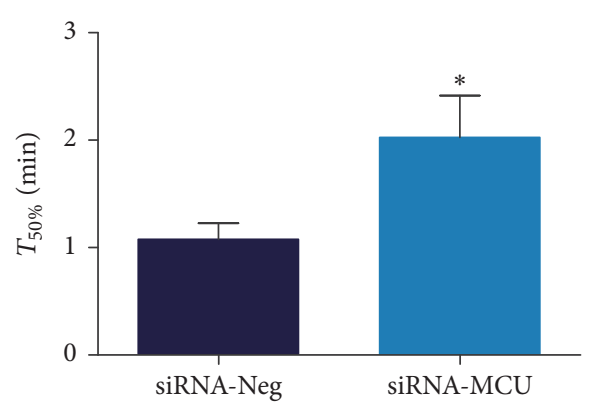

(d)

FIGURE 3: MCU silencing reduces mitochondrial $\mathrm{Ca}^{2+}$ transport. (a) MCU mRNA expression by semiquantitative qRT-PCR in silenced cardiomyocytes, ${ }^{* * *} P<0.001$ versus siRNA-Neg, mean \pm SEM, $n=7$. (b) MCU protein expression, with $\beta$-actin used as a loading control. ${ }^{* * *} P<0.001$ versus siRNA-Neg, mean $\pm \mathrm{SEM}, n=6$. (c) Representative traces of mitochondrial $\mathrm{Ca}^{2+}$ uptake in permeabilized MCU-silenced cardiomyocytes using CG-5N Ca ${ }^{2+}$ indicator after $15 \mu \mathrm{M} \mathrm{Ca}^{2+}$ addition. The experiment was performed in the presence of $1 \mu \mathrm{M}$ CsA. AFU, arbitrary fluorescence units. (d) Time to $50 \%$ decay analysis $\left(T_{50 \%}\right)$ of mitochondrial $\mathrm{Ca}^{2+}$ transport. ${ }^{*} P<0.05$ versus siRNA-Neg, mean \pm $\mathrm{SEM}, n=6$. MCU silencing conditions were using $225 \mathrm{nM}$ of siRNA-MCU at $96 \mathrm{~h}$ of transfection.

$\sim 90 \%$ (Suppl. Figure 1A) and apoptosis was $\sim 3-5 \%$ in both transfected cardiomyocytes at normoxic conditions. At the onset of reoxygenation, we did not find any changes in cell death between the controls (12.6\%) and the MCU-silenced cardiomyocytes (8.2\%), as shown in Figure 6(c). However, after $1.5 \mathrm{~h}$ of reoxygenation, necrosis increased by $46 \%$ in the control cardiomyocytes compared to the MCU-silenced cardiomyocytes $(16.7 \%, P<0.05)$. After 3 h of reoxygenation, the viable cells were preserved in MCU-silenced cardiomyocytes in $60.3 \pm 8 \%$ and then dropped by $30.5 \pm 3.6 \%$ $(P<0.01)$ in the control cardiomyocytes. Apoptotic cell death measurements showed similar results; no significant changes were observed in the level of apoptosis at Nxy or the beginning of reoxygenation between the experimental groups. Nevertheless, we found a twofold decrease in MCUdeficient $(4.3 \pm 1.1)$ versus siRNA-Neg cardiomyocytes $(8.4 \pm$ $0.67)$ after $1.5 \mathrm{~h}$ of reoxygenation $(P<0.01)$. In the same way, after $3 \mathrm{~h}$ of reoxygenation, the apoptosis level increased 1.5-fold in siRNA-Neg cardiomyocytes $(9.12 \pm 0.94$ versus $6.04 \pm 0.5, P<0.05)$. Accordingly, caspases 3 and 7 activities increased by 2 -fold at the onset of reoxygenation in the control cardiomyocytes $(6.86 \pm 0.18)$ compared to the MCU-deficient cardiomyocytes $(3.38 \pm 0.7, P<0.001)$. At the same time, caspase 9 activity increased significantly $(P<0.001)$ in both experimental groups, but, after $1.5 \mathrm{~h}$ of reoxygenation, the activation levels of caspase 9 dropped 1.5-fold in the MCU-deficient cardiomyocytes $(P<$ 0.01). In fact, the activation of caspase 9 and caspases 3 and 7 persisted until $3 \mathrm{~h}$ after reoxygenation in siRNANeg cells compared to the MCU-silenced cardiomyocytes. Additionally, we observed an 18-fold increase in activation of caspase 8 at the onset of reoxygenation in control cells. Nevertheless, we observed a $40 \%$ reduction in caspase 8 activity in MCU-silenced cells compared with control cells $\left(4.95 \pm 0.7\right.$ versus $\left.8.36 \pm 1.6, \mathrm{RLU} \cdot \mathrm{mg}^{-1}\right)$. Overall, these results demonstrate that MCU silencing in cardiomyocytes 


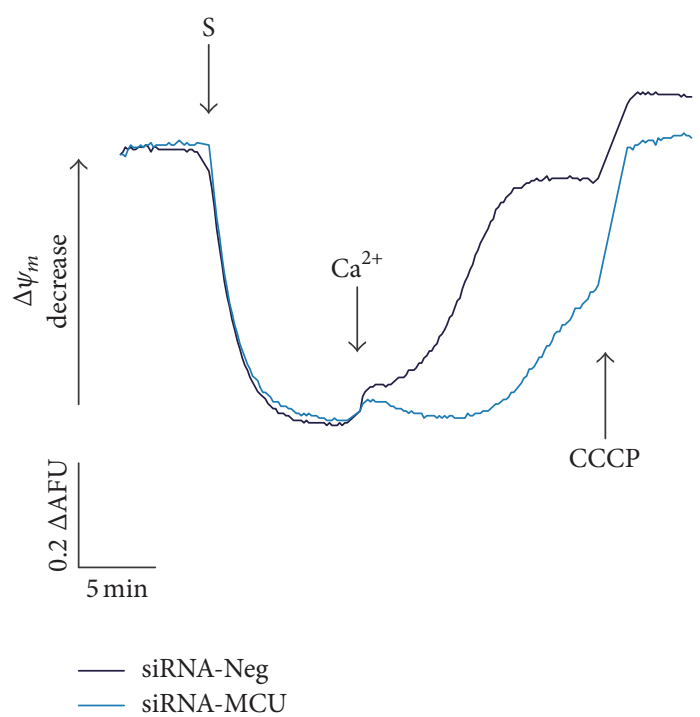

(a)

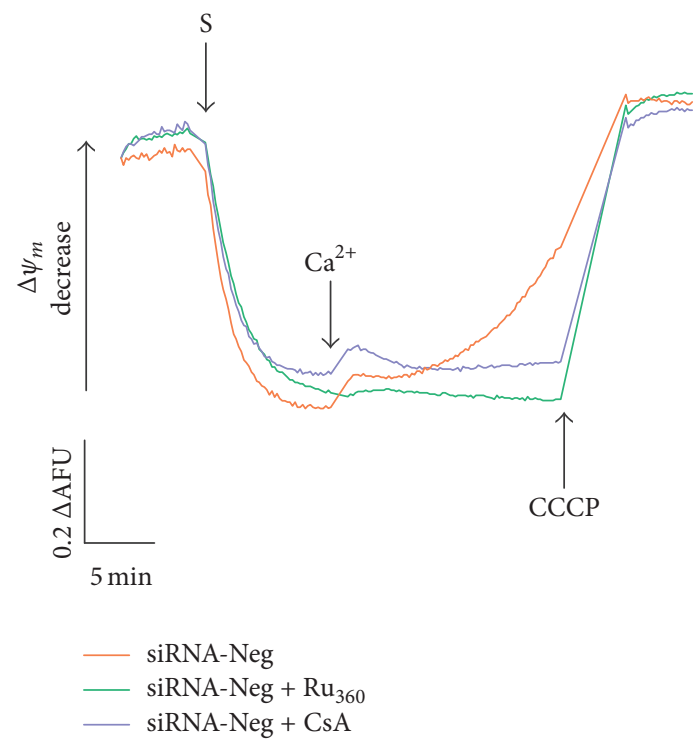

(c)

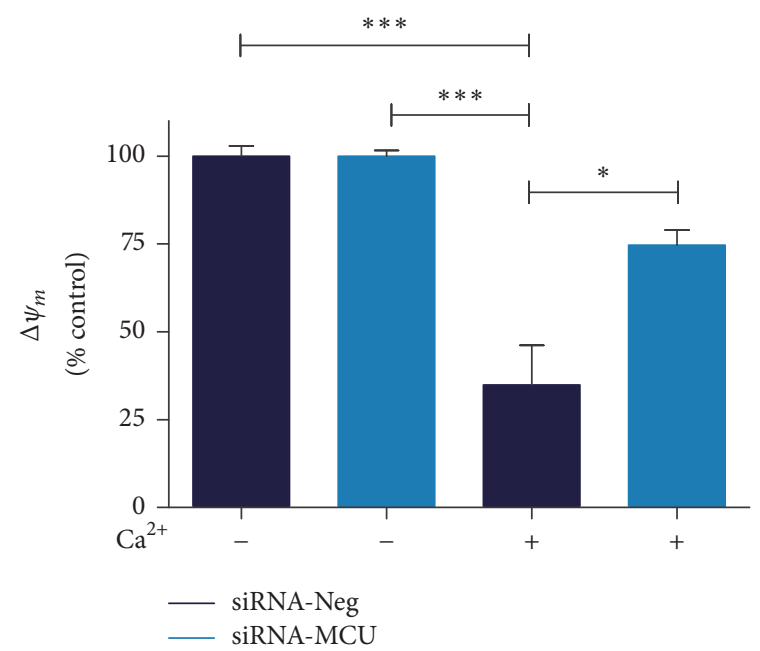

(b)

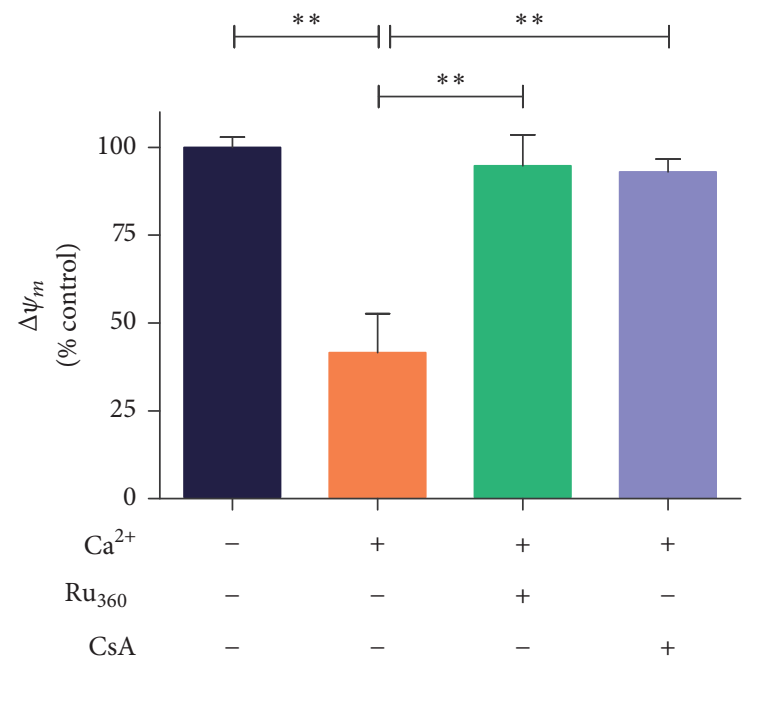

(d)

FIGURE 4: MCU silencing reduces significantly mitochondrial permeability transition by calcium overload. (a) Representative mitochondrial $\Delta \psi_{m}$ traces in permeabilized MCU-silenced cardiomyocytes using $2 \mu \mathrm{M}$ safranin, after $7.5 \mu \mathrm{M} \mathrm{Ca}^{2+}$ addition. siRNA-Neg cardiomyocytes show no difference in $\Delta \psi_{m}$ compared to MCU-silenced cells at baseline. MCU-silenced cardiomyocytes were able to maintain significantly $\Delta \psi_{m}$ after $7.5 \mu \mathrm{M} \mathrm{Ca}^{2+}$ addition. Upon completion of the traces, $20 \mu \mathrm{M}$ CCCP was added as uncoupling. (b) Semiquantitative analysis of $\Delta \psi_{m}$ after $\mathrm{Ca}^{2+}$ addition in transfected cardiomyocytes. ${ }^{*} P<0.05$ versus siRNA-Neg, mean $\pm \mathrm{SEM}, n=3$. (c) Representative mitochondrial safranin $\Delta \psi$ recordings in siRNA-Neg cardiomyocytes treated with $5 \mu \mathrm{M} \mathrm{Ru}_{360}$ or $1 \mu \mathrm{M}$ CsA before $7.5 \mu \mathrm{M} \mathrm{Ca}{ }^{2+}$ pulse. (d) Semiquantitative analysis of $\Delta \psi_{m}$ in siRNA-Neg cardiomyocytes treated with $\mathrm{Ru}_{360}$ or CsA. ${ }^{* *} P<0.01$ versus siRNA-Neg, mean \pm SEM, $n=5-4$. Upon completion of the registers, $20 \mu \mathrm{M}$ CCCP was added as uncoupling. All semiquantitative data is normalized to $100 \%$ of untreated siRNA-Neg cardiomyocytes at basal conditions. AFU, arbitrary fluorescence units. ${ }^{* * *} P<0.001$ versus siRNA-Neg.

reduces necrosis and apoptosis of the hypoxia/reoxygenation injury.

\section{Discussion}

In the heart, $m \mathrm{Ca}^{2+}$ uptake can shape cytosolic calcium signals to regulate some physiological processes, principally matching workload and energy production [23]. Neverthe- less, an excessive uptake of $\mathrm{Ca}^{2+}$ triggers mitochondrial dysfunction through ${ }_{m}$ PTP opening, leading to cell injury by apoptosis and necrosis [5]. In this regard, several studies have suggested that dysregulation of cytosolic $\mathrm{Ca}^{2+}$ which leads to $m \mathrm{Ca}^{2+}$ overload is present in the physiopathology of ischemia/reperfusion (I/R) injury and heart failure (HF) [24]. The MCU channel, the principal $m \mathrm{Ca}^{2+}$ transport system, 


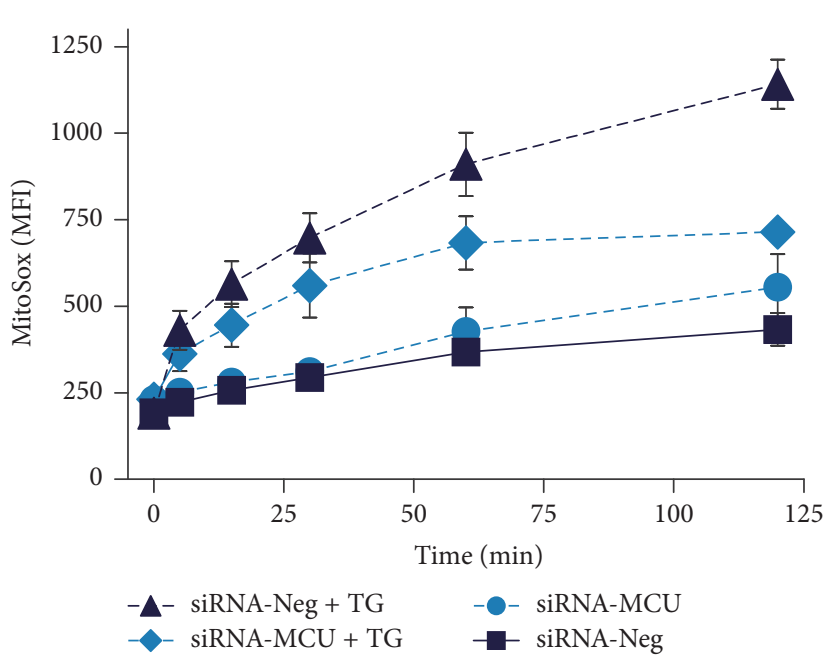

(a)

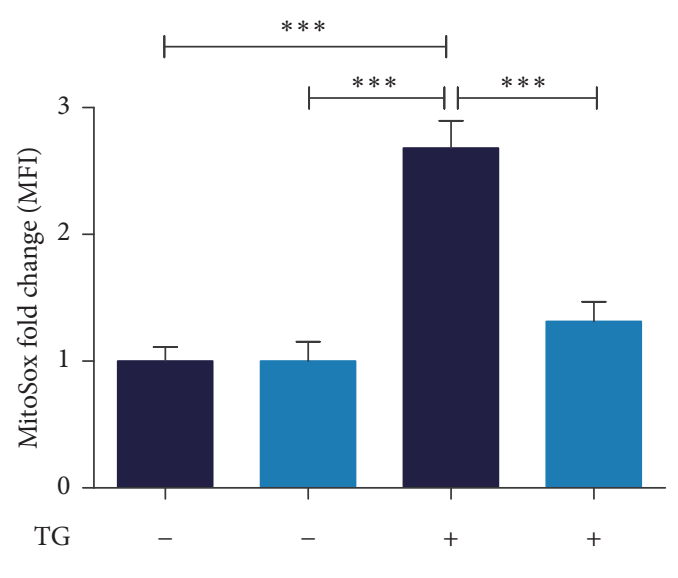

(b)

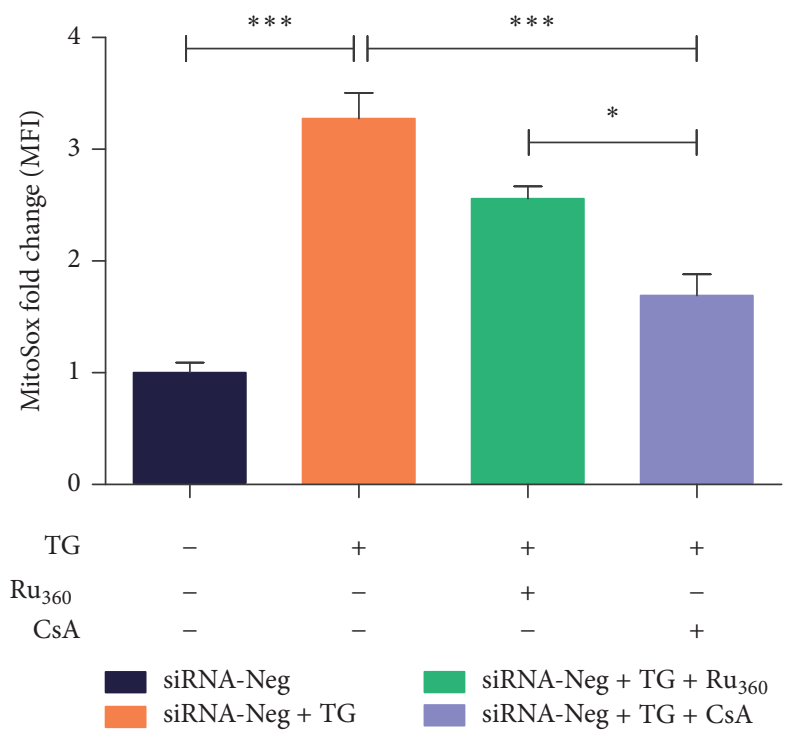

(c)

FIGURE 5: MCU silencing reduces mitochondrial oxidative stress. (a) Time-response curve of mitochondrial ROS (superoxide) production evoked by cytosolic $\mathrm{Ca}^{2+}$ overload with $5 \mu \mathrm{M}$ TG in transfected cardiomyocytes. Measurements were realized over $120 \mathrm{~min}$ of TG treatment and ROS was detected with MitoSOX Red by flow cytometry. (b) ROS levels at 120 min of TG addition is presented as FMI fold change with respect to TG untreated cardiomyocytes. ROS production in siRNA-Neg cardiomyocytes was twofold greater than that in MCU-silenced cardiomyocytes after TG addition, ${ }^{* * *} P<0.001$, mean \pm SEM, $n=5$. (c) ROS production in siRNA-Neg cardiomyocytes pretreated with $5 \mu \mathrm{M} \mathrm{Ru}_{360}$ or $1 \mu \mathrm{M} \mathrm{CsA}$, measured after 120 min of $5 \mu \mathrm{M} \mathrm{TG}$ addition. Data are presented as described previously. ${ }^{*} P<0.05$ and ${ }^{* * *} P<0.001$; mean \pm SEM and $n=6-8$.

carries out this mechanism. However, the precise role in the regulation of $\mathrm{Ca}^{2+}$ handling and its consequences on heart disease remain controversial [25]. Not until recently has the molecular characterization of the MCU been made possible $[11,12]$, allowing for the study of its univocal role in the physiopathology of myocardial diseases. This finding led us to explore the possibility of modulating MCU expression in knockout mice or using a siRNA technology. In this regard, we tested a specific siRNA design to knock down MCU expression in the cardiomyocyte line for an in vitro MCU target validation. After being challenged to a $\mathrm{mCa}^{2+}$ overload, MCU-deficient cells were able to largely sustain $\Delta \psi_{m}$ and retain $\mathrm{Ca}^{2+}$ similarly to those pharmacologically treated with $\mathrm{CsA}$, as expected. Altogether, these findings indicate that MCU silencing confers resistance to ${ }_{m}$ PTP opening $[6,14]$. Furthermore, MCU-silenced cardiomyocytes treated with TG (a SR-Ca ${ }^{2+} /$ ATPase (SERCA) inhibitor), which promotes a burst of cytosolic $\mathrm{Ca}^{2+}$ and later ROS, failed to increase 

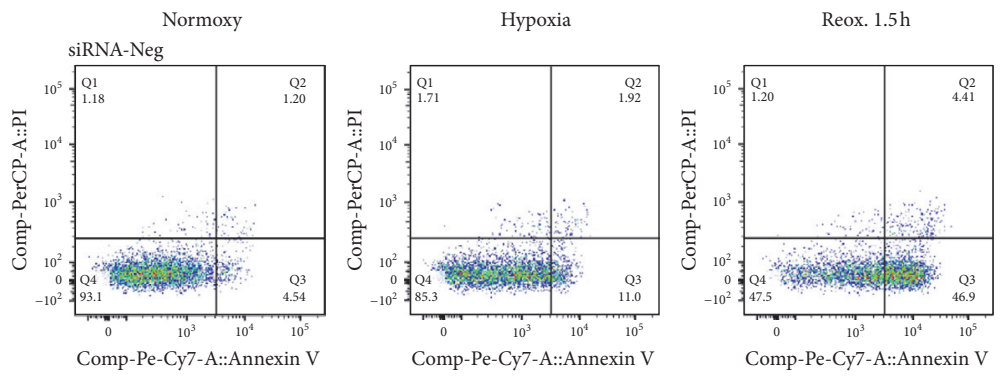

(a)
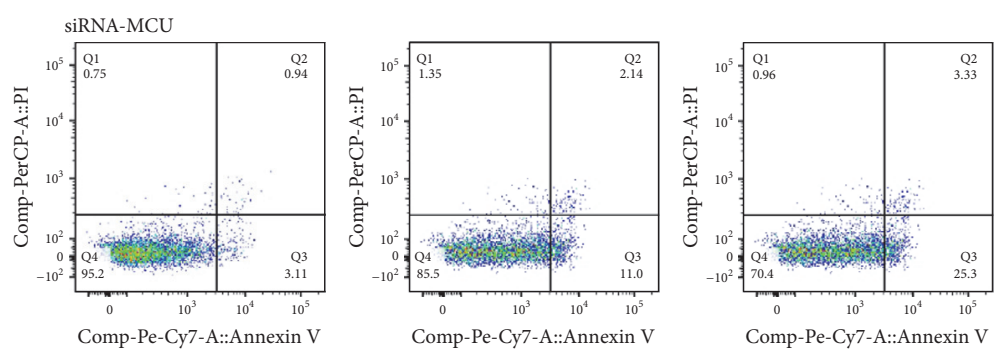

(b)

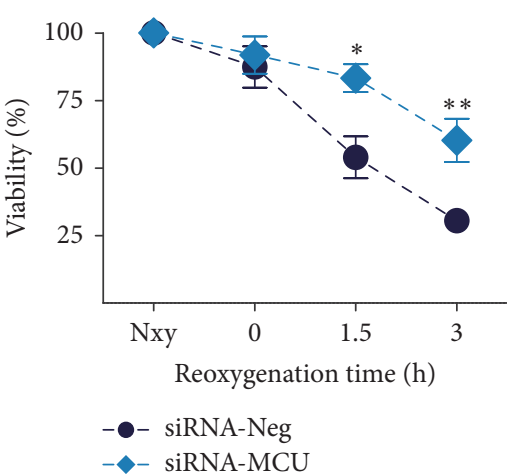

(c)

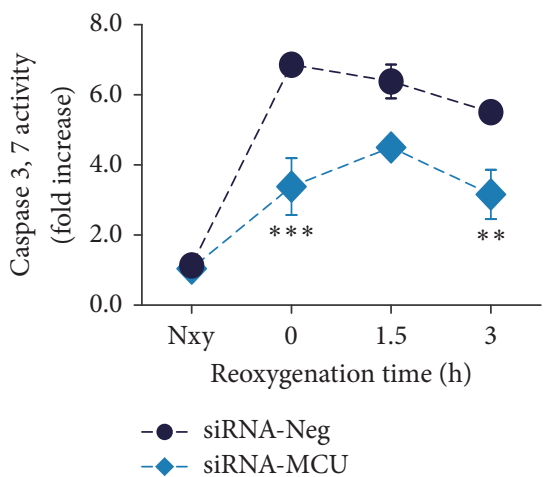

(e)

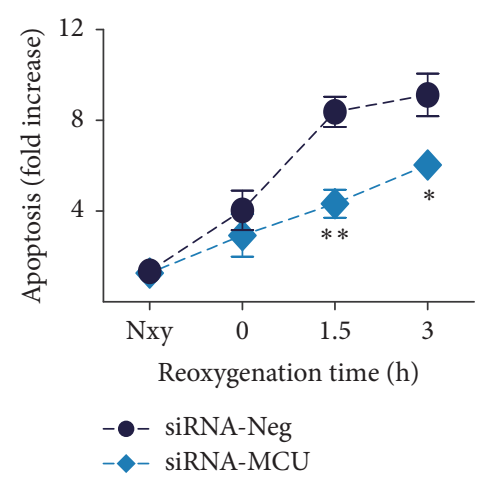

(d)

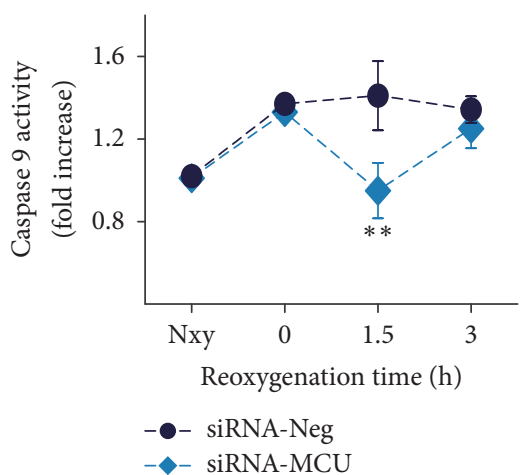

(f)

FIGURE 6: MCU silencing markedly reduced cardiomyocyte cell death in hypoxia/reoxygenation injury. (a and b) Representative dot-plot diagrams of flow cytometry viability/apoptosis analysis of siRNA-Neg and MCU-silenced cardiomyocytes in Nxy, after hypoxia and $1.5 \mathrm{~h}$ reoxygenation time. Viability and apoptosis were determined by PI and Annexin V PE-Cy7 conjugated staining, respectively. Q4 quadrant represents the viable cells, Q2 and Q3 represent the apoptotic cells, while Q1 and Q2 are the necrotic population. (c and d) Reoxygenationtime dependent cardiomyocyte viability and apoptosis at $0,1.5$, and $3 \mathrm{~h}$ reoxygenation, respectively. ${ }^{* *} P<0.01 ;$ mean \pm SEM; $n=7$. Data is presented as percentage of Nxy conditions. (d) Apoptosis was $\sim$ twofold and 1.5-fold increase in siRNA-Neg cardiomyocytes with respect to MCU-silenced cells at 1.5 and $3 \mathrm{~h}$ reoxygenation, respectively. Apoptosis is normalized to Nxy and expressed as fold change. ${ }^{*} P<0.05$, ${ }^{* *} P<0.01$, versus siRNA-Neg cardiomyocytes, mean \pm SEM, $n=7$. (e) Time-dependent activation of caspases 3 and 7 and (f) caspase 9 during reoxygenation. ${ }^{* *} P<0.01,{ }^{* * *} P<0.001$, versus siRNA-Neg cells, mean \pm SEM, and $n=7$; Nxy, normoxic conditions. 
superoxide radical production. Also, after H/R protocol, siRNA-MCU-silenced cardiomyocytes reduced ${ }_{m}$ PTP opening and activation of caspases 8 and 9. In accordance with our results, caspase 8 might initiate the execution phase of cell apoptosis, after which mitochondrial dysfunction induces activation of caspase 9. One potential explanation for this finding is that caspase 8 activation cleaves Bid [26], and then the cleaved Bid activates mitochondrial Bax/Bak and contributes to multiple mitochondrial dysfunction, including the release of the intramembrane space proteins, and activation of apaf-1, which in turn cleaves the proenzyme of caspase 9 into the active form. These observations are similar to those reported when $\mathrm{Ru}_{360}$-MCU was inhibited in in vivo and ex vivo models of $\mathrm{I} / \mathrm{R}[9,10]$, confirming that partial or acute MCU inhibition could be a therapeutic strategy to reduce cell death [27]. Moreover, this cardioprotective effect has been linked to MCU as an ischemic preconditioning (IPC) mediator $[6,28]$. The mechanisms implicated in IPC are not fully understood; however, low levels of $\mathrm{mCa}^{2+}$ generated ROS are involved as a trigger of IPC by activation of survival kinases [29]. Since a large production of ROS during reperfusion contributes importantly to ${ }_{m}$ PTP opening inducing cardiomyocyte death, the controlled ROS production by MCU silencing mimics the IPC cardioprotective effects. Therefore, our findings are in accordance with the observed protection in conditional cardiac-specific $\mathrm{MCU}^{-/-}$mice $[14$, 15]. In this transgenic model, deletion of MCU in adult cardiomyocytes leads to protection from cell death induced by acute damage such as ischemia-reperfusion injury. However, the results in MCU-knockout constitutive animals are still controversial. For instance, during reperfusion injury, MCU-knockout hearts were similar to control hearts, and CsA did not exert a protective effect. This suggests that $\mathrm{Ca}^{2+}$-independent death pathways take place in the absence of MCU and that alternative mechanisms exist for $\mathrm{Ca}^{2+}$ entry [30]. Of note, inbred MCU-knockout mice are not viable because they are embryonically lethal; only mixedstrain MCU-knockout mice are viable [31]. In addition to this controversy, recent results in MCU overexpressing mice are more resistant to reperfusion injury in part due to an enhanced activity of survival kinases [32].

In addition to defining the contribution of MCU activity in pathologies, the discovery of therapeutic strategies that modulate MCU activity will be extremely important for the future development of putative MCU-targeting therapies. Here, using siRNA or several pharmacological strategies (such as $\mathrm{Ru}_{360}$ or CsA), we attempted to diminish ${ }_{m}$ PTP opening or reduce $m \mathrm{Ca}^{2+}$ overload in order to decrease the likelihood of arrhythmias and postmyocardial infarction cardiac dysfunction [2]. In this regard, in vitro and ex vivo studies of cytosolic $\mathrm{Ca}^{2+}$ overload and IR injury have shown that CsA is a potent inhibitor of ${ }_{m} \mathrm{PTP}$, protecting against reperfusion cardiomyocyte death $[8,33]$. Indeed, CsA application in small animal models at the onset of reperfusion has demonstrated a reduction of the myocardial infarct area by $\sim 45 \%$ [34] by suppressing $\Delta \psi_{m}$ loss, NADH oxidation, $\mathrm{Ca}^{2+}$ release, and mitochondrial swelling [35]. Accordingly, some clinical trials have been performed to determine its protective effect from reperfusion injury in patients with myocardial infarction [36]. Nevertheless, a recent metaanalysis of randomized controlled trials reveals that CsA could not have protective effects towards reperfusion injury in clinical patients [37]. The cause of these effects is not yet clear, but it could be because CsA is an immunosuppressive agent that has multiple targets such as cyclophilins and calcineurin [38]. Additionally, CsA only increases the threshold of ${ }_{m}$ PTP inducers, so it would be desirable to explore another strategy to prevent the formation of ${ }_{m}$ PTP and reperfusion injury. On the other hand, the use of $\mathrm{Ru}_{360}$ as a specific inhibitor of the MCU has been used in intact cardiac cells [7], isolated hearts [6, 10], and murine models [9] which provided protection against reperfusion injury, improving mechanical parameters, and decreasing infarct size and intracellular enzymes release $[9,39]$. However, their pharmacokinetic parameters, bioavailability, and side effects have not been completely described.

Moreover, these therapeutic strategies that reduce ischemic injury could be beneficial to slow the progression of HF. In this regard, Santulli et al. [40] recently demonstrated that an intracellular $\mathrm{Ca}^{2+}$ leak could cause mitochondrial $\mathrm{Ca}^{2+}$ overload and dysfunction in HF murine models. In particular, a sarcoplasmic reticulum $\mathrm{Ca}^{2+}$ leak can establish a pathological feedback with mitochondria in which mitochondrial dysfunction increases ROS production, which consequently leads to oxidation/nitrosylation of some important sarcoplasmic reticulum channels such as RyR2, enhancing the diastolic $\mathrm{Ca}^{2+}$ leak and affecting cell contractility. Moreover, we found that selective MCU inhibition has the therapeutic potential to prevent catecholamine-induced toxicity as observed in HF [41]. In this regard, Anderson's group using MCU dominant-negative transgenic mice confirmed our findings of MCU's role on catecholamine response, because their mice were incapable of reaching catecholamine response $[14,27]$. These novel data provide experimental rationale to explore the role of MCU during HF development.

At present, knockdown of gene expression by siRNA technologies offers a potent therapeutic approach to specific modulation of gene targeting [42]. siRNA therapeutics is suitable for drug use because it does not require genome integration and can be inexpensive and easily synthesized. Since a rational design of siRNA can specifically inhibit endogenous gene expression, it can modulate any diseaserelated gene expression [43]. Because of their great therapeutic potential, at least 20 siRNA-based drugs have now entered clinical trials in humans [43]. However, siRNA molecules are unstable in the serum and have shown poor cellular uptake and immunogenicity [44]. In this regard, the successful application of siRNA for therapy requires the development of effective drug delivery systems, in particular, nanovectors [45]. Recently, endothelial dysfunction present in HF has been explored as a novel avenue for the delivery of nanovectors, and the resulting endothelial permeability opens the field to nanotechnology-based therapies that could reach the myocardium through dysfunctional permeable endothelium [46]. In a murine model of $\mathrm{HF}$, a 
passive intracardiac accumulation of high concentrations of nanocarriers occurred after a single application. Compared to the normal heart tissues, the accumulation of nanovectors was 12 times higher in HF animals [47]. This approach should be used as a potential avenue for siRNA-MCU therapy in reperfusion injury or $\mathrm{HF}$, potentially translating towards novel therapies that might improve patient outcomes.

\section{Conclusion}

In summary, as the first proof of concept, we have shown that MCU silencing by specific siRNA reduces in vitro $\mathrm{H} / \mathrm{R}$ injury as seen by cardiomyocyte death abatement. Therefore, this knowledge will allow for the development of a suitable delivery system to test the therapeutic potential of this siRNA in an in vivo model of mitochondrial calcium overload and dysfunction as those present in HF. In this context, the novel MCU druggability should be a fertile area of research in the future.

\section{Abbreviations}

AFU: Arbitrary fluorescence units

CG-5N: Calcium Green-5N

CCCP: Cyanide $m$-chlorophenyl hydrazone

CsA: Cyclosporin A

ETC: $\quad$ Electron transport chain

HR: Hypoxia/reoxygenation

MFI: Median fluorescence intensity

$m \mathrm{Ca}^{2+}:$ Mitochondrial calcium

MCU: Mitochondrial calcium uniporter

${ }_{m}$ PTP: Mitochondrial permeability transition pore

$\Delta \psi_{m}: \quad$ Mitochondrial membrane potential

$\mathrm{MVO}_{2}$ : Myocardial oxygen consumption

Nxy: Normoxy

PI: $\quad$ Propidium iodide

RLU: Relative luminescence units

ROS: $\quad$ Reactive oxygen species

SERCA: Sarco/endoplasmic reticulum calcium-ATPase

TG: Thapsigargin

TI: $\quad$ Tyrode ischemic solution

Uniplex: Mitochondrial calcium uniporter holocomplex.

\section{Disclosure}

This work was submitted in partial fulfillment of the requirements for the Ph.D. degree of Yuriana Oropeza-Almazán for the Doctorate in Biotechnology of Tecnológico de Monterrey.

\section{Competing Interests}

The authors declare that they have no competing interests.

\section{Authors' Contributions}

Conception and design of research were done by Gerardo García-Rivas and Yuriana Oropeza-Almazán. Yuriana Oropeza-Almazán, Eduardo Vázquez-Garza, and Héctor ChapoyVillanueva performed experiments; Yuriana Oropeza-Alma- zán, Eduardo Vázquez-Garza, and Héctor Chapoy-Villanueva analyzed data; Yuriana Oropeza-Almazán and Gerardo García-Rivas drafted manuscript; Yuriana Oropeza-Almazán, Eduardo Vázquez-Garza, Héctor Chapoy-Villanueva, Guillermo Torre-Amione, and Gerardo García-Rivas interpreted results of experiments; Yuriana Oropeza-Almazán prepared figures; Gerardo García-Rivas and Guillermo Torre-Amione edited and revised manuscript. Eduardo Vázquez-Garza and Héctor Chapoy-Villanueva contribute equally.

\section{Acknowledgments}

The authors thank Dr. Arturo Chávez-Reyes for their support with siRNA design and critical review of experimental results, Silvia Cárdenas Rodríguez, M.D., and Miguel A. Flores, B.S., for exceptional technical assistance. They also thank Valeria Oropeza for editing the figures. This work was partially supported by Endowed Chair in Cardiology (Tecnológico de Monterrey, 0020CAT131) as well as CONACYT Grants 151136, 133591, and 269399 and Fronteras de la Ciencia grant (0682) and Xignus Research Fund. Postdoctoral fellowship (CONACYT to Eduardo Vázquez-Garza and Héctor Chapoy-Villanueva) is also acknowledged.

\section{References}

[1] D. J. Hausenloy, E. A. Boston-Griffiths, and D. M. Yellon, "Cyclosporin A and cardioprotection: from investigative tool to therapeutic agent," British Journal of Pharmacology, vol. 165, no. 5, pp. 1235-1245, 2012.

[2] D. M. Yellon and D. J. Hausenloy, "Myocardial reperfusion injury," The New England Journal of Medicine, vol. 357, no. 11, pp. 1121-1135, 2007.

[3] S.-M. Kang, S. Lim, H. Song et al., "Allopurinol modulates reactive oxygen species generation and $\mathrm{Ca} 2+$ overload in ischemiareperfused heart and hypoxia-reoxygenated cardiomyocytes," European Journal of Pharmacology, vol. 535, no. 1-3, pp. 212-219, 2006.

[4] A. P. Halestrap, "Mitochondria and reperfusion injury of the heart-a holey death but not beyond salvation," Journal of Bioenergetics and Biomembranes, vol. 41, no. 2, pp. 113-121, 2009.

[5] A. P. Halestrap, "What is the mitochondrial permeability transition pore?" Journal of Molecular and Cellular Cardiology, vol. 46, no. 6, pp. 821-831, 2009.

[6] G. D. J. García-Rivas, A. Guerrero-Hernández, G. GuerreroSerna, J. S. Rodríguez-Zavala, and C. Zazueta, "Inhibition of the mitochondrial calcium uniporter by the oxo-bridged dinuclear ruthenium amine complex $\left(\mathrm{Ru}_{360}\right)$ prevents from irreversible injury in postischemic rat heart," FEBS Journal, vol. 272, no. 13, pp. 3477-3488, 2005.

[7] M. A. Matlib, Z. Zhou, S. Knight et al., "Oxygen-bridged dinuclear ruthenium amine complex specifically inhibits $\mathrm{Ca}^{2+}$ uptake into mitochondria in vitro and in situ in single cardiac myocytes," Journal of Biological Chemistry, vol. 273, no. 17, pp. 10223-10231, 1998.

[8] E. J. Griffiths, C. J. Ocampo, J. S. Savage, M. D. Stern, and H. S. Silverman, "Protective effects of low and high doses of cyclosporin A against reoxygenation injury in isolated rat cardiomyocytes are associated with differential effects on mitochondrial calcium levels," Cell Calcium, vol. 27, no. 2, pp. 87-95, 2000. 
[9] G. J. García-Rivas, K. Carvajal, F. Correa, and C. Zazueta, " $\mathrm{Ru}_{360}$, a specific mitochondrial calcium uptake inhibitor, improves cardiac post-ischaemic functional recovery in rats in vivo," British Journal of Pharmacology, vol. 149, no. 7, pp. 829837, 2006.

[10] F. Correa, V. Soto, and C. Zazueta, "Mitochondrial permeability transition relevance for apoptotic triggering in the postischemic heart," The International Journal of Biochemistry \& Cell Biology, vol. 39, no. 4, pp. 787-798, 2007.

[11] J. M. Baughman, F. Perocchi, H. S. Girgis et al., "Integrative genomics identifies MCU as an essential component of the mitochondrial calcium uniporter," Nature, vol. 476, no. 7360, pp. 341-345, 2011.

[12] D. De Stefani, A. Raffaello, E. Teardo, I. Szabó, and R. Rizzuto, "A forty-kilodalton protein of the inner membrane is the mitochondrial calcium uniporter," Nature, vol. 476, no. 7360, pp. 336-340, 2011.

[13] D. De Stefani, R. Rizzuto, and T. Pozzan, "Enjoy the trip: calcium in mitochondria back and forth," Annual Review of Biochemistry, vol. 85, pp. 161-192, 2016.

[14] J. Q. Kwong, X. Lu, R. N. Correll et al., "The mitochondrial calcium uniporter selectively matches metabolic output to acute contractile stress in the heart," Cell Reports, vol. 12, no. 1, pp. 1522, 2015.

[15] T. S. Luongo, J. P. Lambert, A. Yuan et al., “The mitochondrial calcium uniporter matches energetic supply with cardiac workload during stress and modulates permeability transition," Cell Reports, vol. 12, no. 1, pp. 23-34, 2015.

[16] C.-F. Xu and J. Wang, "Delivery systems for siRNA drug development in cancer therapy," Asian Journal of Pharmaceutical Sciences, vol. 10, no. 1, pp. 1-12, 2015.

[17] J. E. Zuckerman and M. E. Davis, "Clinical experiences with systemically administered siRNA-based therapeutics in cancer," Nature Reviews Drug Discovery, vol. 14, no. 12, pp. 843-856, 2015.

[18] M. Patron, V. Checchetto, A. Raffaello et al., "MICU1 and MICU2 finely tune the mitochondrial $\mathrm{Ca}^{2+}$ uniporter by exerting opposite effects on MCU activity," Molecular Cell, vol. 53, no. 5, pp. 726-737, 2014.

[19] K. A. P. Oliveira, K. G. Zecchin, L. C. Alberici, R. F. Castilho, and A. E. Vercesi, "Simvastatin inducing PC3 prostate cancer cell necrosis mediated by calcineurin and mitochondrial dysfunction," Journal of Bioenergetics and Biomembranes, vol. 40, no. 4, pp. 307-314, 2008.

[20] P. Mukhopadhyay, M. Rajesh, K. Yoshihiro, G. Haskó, and P. Pacher, "Simple quantitative detection of mitochondrial superoxide production in live cells," Biochemical and Biophysical Research Communications, vol. 358, no. 1, pp. 203-208, 2007.

[21] M. Zhao, L. Sun, X.-J. Yu et al., "Acetylcholine mediates AMPK-dependent autophagic cytoprotection in H9c2 cells during hypoxia/reoxygenation injury," Cellular Physiology and Biochemistry, vol. 32, no. 3, pp. 601-613, 2013.

[22] P. Bernardi, F. Di Lisa, F. Fogolari, and G. Lippe, "From ATP to PTP and back: a dual function for The mitochondrial ATP synthase," Circulation Research, vol. 116, no. 11, pp. 1850-1862, 2015.

[23] C. Mammucari, A. Raffaello, D. V. Reane, and R. Rizzuto, "Molecular structure and pathophysiological roles of the Mitochondrial Calcium Uniporter," Biochimica et Biophysica ActaMolecular Cell Research, vol. 1863, no. 10, pp. 2457-2464, 2016.
[24] M. Luo and M. E. Anderson, "Mechanisms of altered $\mathrm{Ca}^{2+}$ handling in heart failure," Circulation Research, vol. 113, no. 6, pp. 690-708, 2013.

[25] B. S. Jhun, J. Mishra, S. Monaco et al., "The mitochondrial $\mathrm{Ca}^{2+}$ uniporter: regulation by auxiliary subunits and signal transduction pathways," American Journal of Physiology-Cell Physiology, vol. 311, no. 1, pp. C67-C80, 2016.

[26] X. Luo, I. Budihardjo, H. Zou, C. Slaughter, and X. Wang, "Bid, a $\mathrm{Bcl} 2$ interacting protein, mediates cytochrome $\mathrm{c}$ release from mitochondria in response to activation of cell surface death receptors," Cell, vol. 94, no. 4, pp. 481-490, 1998.

[27] T. P. Rasmussen, Y. Wu, M.-L. A. Joiner et al., "Inhibition of MCU forces extramitochondrial adaptations governing physiological and pathological stress responses in heart," Proceedings of the National Academy of Sciences of the United States of America, vol. 112, no. 29, pp. 9129-9134, 2015.

[28] S.-Z. Zhang, Q. Gao, C.-M. Cao, I. C. Bruce, and Q. Xia, "Involvement of the mitochondrial calcium uniporter in cardioprotection by ischemic preconditioning," Life Sciences, vol. 78, no. 7, pp. 738-745, 2006.

[29] D. J. Hausenloy and D. M. Yellon, "Survival kinases in ischemic preconditioning and postconditioning," Cardiovascular Research, vol. 70, no. 2, pp. 240-253, 2006.

[30] X. Pan, J. Liu, T. Nguyen et al., "The physiological role of mitochondrial calcium revealed by mice lacking the mitochondrial calcium uniporter," Nature Cell Biology, vol. 15, no. 12, pp. 14641472, 2013.

[31] E. Murphy, X. Pan, T. Nguyen, J. Liu, K. M. Holmström, and T. Finkel, "Unresolved questions from the analysis of mice lacking MCU expression," Biochemical and Biophysical Research Communications, vol. 449, no. 4, pp. 384-385, 2014.

[32] F. Di Lisa, M. Campesan, T. Zaglia, D. De Stefani, M. Mongillo, and R. Rizzuto, "Mitochondrial $\mathrm{Ca}^{2+}$ and ROS formation in cardiac injury and protection," Biochimica et Biophysica Acta (BBA)_Bioenergetics, vol. 1857, p. ell, 2016.

[33] D. J. Hausenloy, H. L. Maddock, G. F. Baxter, and D. M. Yellon, "Inhibiting mitochondrial permeability transition pore opening: a new paradigm for myocardial preconditioning?" Cardiovascular Research, vol. 55, no. 3, pp. 534-543, 2002.

[34] S. Y. Lim, D. J. Hausenloy, S. Arjun et al., "Mitochondrial cyclophilin-D as a potential therapeutic target for postmyocardial infarction heart failure," Journal of Cellular and Molecular Medicine, vol. 15, no. 11, pp. 2443-2451, 2011.

[35] A.-C. Wei, T. Liu, S. Cortassa, R. L. Winslow, and B. O’Rourke, "Mitochondrial $\mathrm{Ca}^{2+}$ influx and efflux rates in guinea pig cardiac mitochondria: low and high affinity effects of cyclosporine A," Biochimica et Biophysica Acta-Molecular Cell Research, vol. 1813, no. 7, pp. 1373-1381, 2011.

[36] P. Z. Gerczuk and R. A. Kloner, "An update on cardioprotection: a review of the latest adjunctive therapies to limit myocardial infarction size in clinical trials," Journal of the American College of Cardiology, vol. 59, no. 11, pp. 969-978, 2012.

[37] K. Song, S. Wang, and D. Qi, "Effects of cyclosporine on reperfusion injury in patients: a meta-analysis of randomized controlled trials," Oxidative Medicine and Cellular Longevity, vol. 2015, Article ID 287058, 6 pages, 2015.

[38] A. P. Halestrap and P. Pasdois, "The role of the mitochondrial permeability transition pore in heart disease," Biochimica et Biophysica Acta-Bioenergetics, vol. 1787, no. 11, pp. 1402-1415, 2009. 
[39] K. Shintani-Ishida, M. Inui, and K.-I. Yoshida, "Ischemiareperfusion induces myocardial infarction through mitochondrial Ca ${ }^{2+}$ overload," Journal of Molecular and Cellular Cardiology, vol. 53, no. 2, pp. 233-239, 2012.

[40] G. Santulli, W. Xie, S. R. Reiken, and A. R. Marks, "Mitochondrial calcium overload is a key determinant in heart failure," Proceedings of the National Academy of Sciences of the United States of America, vol. 112, no. 36, pp. 11389-11394, 2015.

[41] E. Fernández-Sada, C. Silva-Platas, C. A. Villegas et al., "Cardiac responses to $\beta$-adrenoceptor stimulation is partly dependent on mitochondrial calcium uniporter activity," British Journal of Pharmacology, vol. 171, no. 18, pp. 4207-4221, 2014.

[42] D. Kim and J. Rossi, "RNA mechanisms and applications," Biotechniques, vol. 44, pp. 613-616, 2009.

[43] B. A. Sullenger and S. Nair, "From the RNA world to the clinic," Science, vol. 352, no. 6292, pp. 1417-1420, 2016.

[44] F. Alexis, E. Pridgen, L. K. Molnar, and O. C. Farokhzad, "Factors affecting the clearance and biodistribution of polymeric nanoparticles," Molecular Pharmaceutics, vol. 5, no. 4, pp. 505515, 2008.

[45] K. Whitehead, R. Langer, and D. Anderson, "Knocking down barriers: advances in siRNA delivery," Nature Reviews Drug Discovery, vol. 8, pp. 129-138, 2009.

[46] W. G. Roberts and G. E. Palade, "Increased microvascular permeability and endothelial fenestration induced by vascular endothelial growth factor," Journal of Cell Science, vol. 108, no. 6, pp. 2369-2379, 1995.

[47] G. U. Ruiz-Esparza, V. Segura-Ibarra, A. M. Cordero-Reyes et al., "A specifically designed nanoconstruct associates, internalizes, traffics in cardiovascular cells, and accumulates in failing myocardium: a new strategy for heart failure diagnostics and therapeutics," European Journal of Heart Failure, vol. 18, no. 2, pp. 169-178, 2016. 


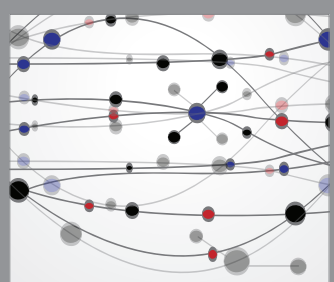

The Scientific World Journal
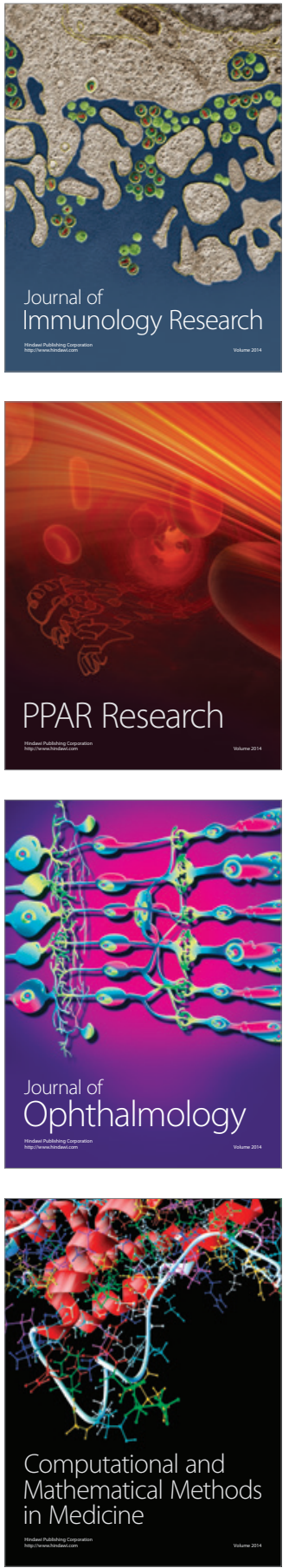

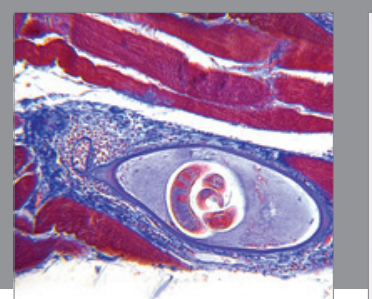

Gastroenterology Research and Practice
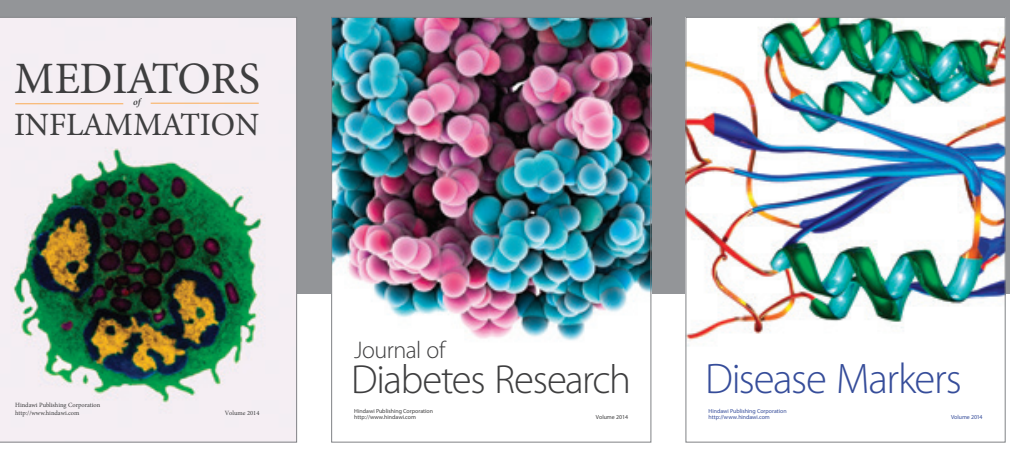

Disease Markers

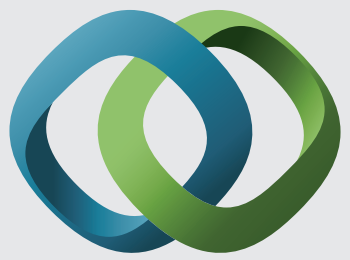

\section{Hindawi}

Submit your manuscripts at

https://www.hindawi.com
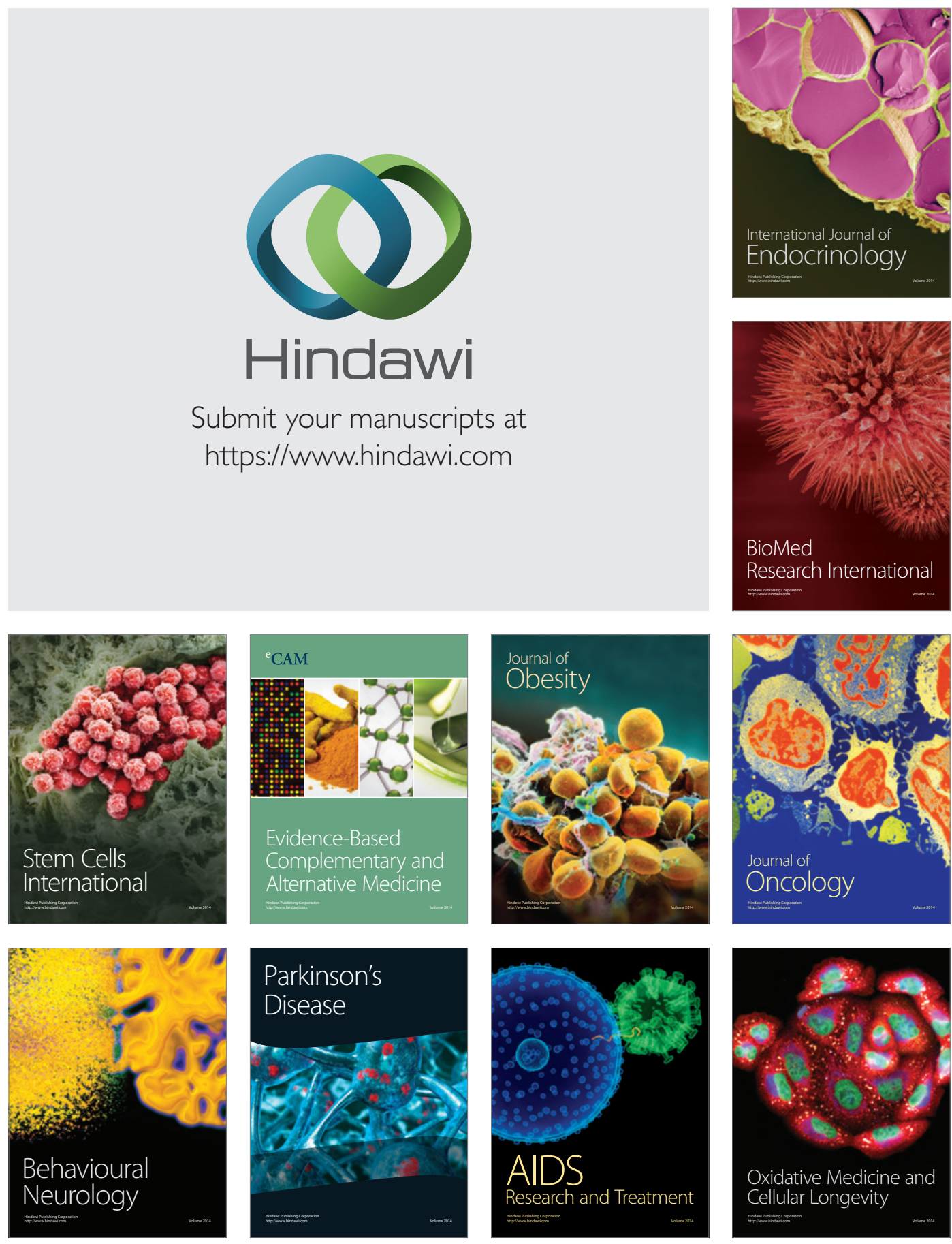